\title{
TİNH TRẠNG DINH DƯỠNG CỦA HỌC SINH TẠI HAI TRƯỜNG PHŌ THÔNG DÂN TỘC NỘI TRÚ TRUNG HỌC CO' SỞ TỈNH YÊN BÁl NĂM 2019
}

\author{
Trương Thị Thùy Dương, Trần Thị Hồng Vân, \\ Nguyễn Thị Thanh Tâm và Trần Thị Huyền Trang ${ }^{\bowtie}$ \\ Trường Đại học Y Dược, Đại học Thái Nguyên
}

Nghiên cứu mô tả cắt ngang trên 535 học sinh nhằm mô tả tình trạng dinh dưỡng của học sinh dân tộc thiểu số trường phổ thông dân tộc nội trú trung học cơ sở huyện Yên Bình và huyện Trấn Yên, tỉnh Yên Bái năm 2019. Thu thập số liệu bằng phương pháp phỏng vấn bằng bộ câu hỏi được thiết kế sãn và cân đo trực tiếp. Sử dụng chuẩn tham khảo quốc tế để đánh giá tình trạng dinh dưỡng. Kết quả cho thấy tỷ lệ suy dinh dương thể thấp còi của học sinh dân tộc thiểu số là $15,0 \%$ cao hơn so với tỷ lệ suy dinh dương thể gầy còm là 4,5\%. Tỷ lệ học sinh dân tộc thiểu số thừa cân, béo phì là $7,3 \%$. Không có sự khác biệt có ý nghĩa thống kê về tỷ lệ suy dinh dưỡng cũng như tỷ lệ thừa cân, béo phì theo độ tuổi của học sinh tại 2 trường phổ thông dân tộc nội trú trung học cơ sở thuộc hai huyện của tỉnh Yên Bái $(p>0,05)$.

Từ khoá: Học sinh, dân tộc thiểu số, phổ thông dân tộc nội trú, trung học cơ sở, tình trạng dinh dưỡng, huyện Yên Bình, huyện Trấn Yên, tỉnh Yên Bái.

\section{I. ĐẠT VẤN ĐỀ}

Suy dinh dưỡng (SDD) ở trẻ em vẫn còn là một vấn đề lớn ở các quốc gia đang phát triển. Tại Việt Nam, mặc dù đã thực hiện nhiều nỗ lực nhằm cải thiện tình trạng dinh dưỡng và sức khoẻ nhưng tỷ lệ SDD thấp còi ở trẻ em lứa tuổi học đường từ 5 đến 19 tuổi trên toàn quốc vẫn còn ở mức cao là $14,8 \%{ }^{1}{ }^{1}$ Những tỷ lệ SDD này phân bố không đồng đều, đặc biệt ở vùng nông thôn có tỷ lệ SDD cao hơn so với thành thị. ${ }^{2}$ Bên cạnh đó, là vấn đề đáng báo động về sự gia tăng tỷ lệ thừa cân, béo phì (TC - BP). Tỷ lệ TC - BP ở trẻ 5 - 19 tuổi tăng cao từ 8,5\% năm 2010 lên đến 19,0\% năm 2020, trong đó tỷ lệ thừa cân, béo phì khu vực nông thôn (18,3\%) cũng gia tăng đáng kể .1,3

Đã có nhiều nghiên cứu để đánh giá tỷ lệ

Tác giả liên hệ: Trần Thị Huyền Trang,

Trường Đại học Y Dược, Đại học Thái Nguyên

Email: duonghuyanhphuong8888@gmail.com

Ngày nhận: 30/06/2021

Ngày được chấp nhận: 25/07/2021
SDD và TC - BP ở trẻ dưới 5 tuổi và lứa tuổi người trưởng thành, trong khi chỉ có một số ít các nghiên cứu được thực hiện ở lứa tuổi học đường, đặc biệt độ tuổi tiền dậy thì và dậy thì. Hơn nữa, rất ít các nghiên cứu liên quan đến đối tượng học sinh dân tộc thiểu số. Do đó, nghiên cứu của chúng tôi thực sự cần thiết, đây sẽ là cơ sở để từ đó đưa ra các biện pháp kịp thời, nhằm giảm thiểu những vấn đề sức khoẻ liên quan đến dinh dưỡng của học sinh lứa tuổi học đường, giúp xây dựng thế hệ chủ nhân tương lai của đất nước vững mạnh. Đề tài của chúng tôi tiến hành với mục tiêu mô tả tình trạng dinh dưỡng của học sinh dân tộc thiểu số trường phổ thông dân tộc nội trú trung học cơ sở huyện Yên Bình và huyện Trấn Yên, tỉnh Yên Bái năm 2019.

\section{II. ĐỐI TƯƠ'NG VÀ PHƯƠNG PHÁP}

\section{1. Đối tượng}

Học sinh dân tộc thiểu số trường phổ thông dân tộc nội trú trung học cơ sở tại huyện Yên Bình và huyện Trấn Yên, tỉnh Yên Bái. 
Tiêu chuẩn lựa chọn đối tượng nghiên cứu

Học sinh dân tộc thiểu số các trường Phổ thông Dân tộc nội trú Trung học Cơ sở (PTDTNT THCS) thuộc 2 huyện của tỉnh Yên Bái tự nguyện tham gia vào nghiên cứu và có khả năng trả lời phỏng vấn.

\section{Tiêu chuẩn loại trù̀}

Tất cả những học sinh từ chối tham gia nghiên cứu, những học sinh vắng mặt trong ngày điều tra.

\section{Phương pháp}

\section{Thời gian và địa điểm nghiên cứu}

Thời gian nghiên cứu: Từ tháng 9/2019 đến tháng 1/2020 (thời gian thu thập số liệu từ tháng 9 đến tháng 12 năm 2019).

Địa điểm nghiên cứu: Trường PTDTNT THCS huyện Yên Bình và trường PTDTNT THCS huyện Trấn Yên, tỉnh Yên Bái.

Thiết kế nghiên cứu: Nghiên cứu mô tả, thiết kế cắt ngang.

\section{Cỡ mẫu và phương pháp chọn mẫu}

Cỡ mẫu

Cỡ mẫu toàn bộ số học sinh dân tộc thiểu số của 2 trường PTDTNT THCS tại 2 huyện của tỉnh Yên Bái. Tổng cỡ mẫu $\mathrm{n}=535$ học sinh.

Phương pháp chọn mẫu: Chọn chủ đích 2 huyện của tỉnh Yên Bái (huyện Trấn Yên và Yên Bình). Mỗi huyện có một trường. Tại mỗi trường chọn toàn bộ học sinh của trường đó theo danh sách học sinh nhà trường cung cấp (trường PTDTNT THCS huyện Yên Bình có 273 học sinh và PTDTNT THCS huyện Trấn Yên có 262 học sinh).

\section{Các nhóm chỉ số nghiên cứu}

- Tình trạng dinh dưỡng của đối tượng nghiên cứu.

+ Phân bố đối tượng theo nhóm tuổi, giới.

+ Cân nặng, chiều cao trung bình, chỉ số khối cơ thể (BMI).

+ Tỷ lệ suy dinh dưỡng, tỷ lệ thừa cân, béo phì.

Phương pháp thu thập số liệu
Thu thập các thông tin về nhân khẩu học, thông tin về nhân trắc

Sử dụng bộ câu hỏi điều tra được thiết kế sẵn.

\section{Thu thập về chỉ số nhân trắc}

Cân nặng: sử dụng cân SECA của Nhật Bản.

Chiều cao được đo bằng thước gỗ của UNICEF.

Cách tính tuổi của học sinh: Tuổi của đối tượng tham gia nghiên cứu được tính bằng cách lấy ngày tháng năm điều tra trừ đi ngày tháng năm sinh dương lịch của học sinh.

\section{Đánh giá tình trạng dinh dưỡng}

Dựa theo bảng phân loại Z - score của WHO năm 2007 cho trẻ từ 10 đến 19 tuổi:

- Đánh giá chỉ số Z - score chiều cao theo tuổi:

+ SDD thể thấp còi: $Z$ - score < - 2SD.

+ Tình trạng dinh dưỡng bình thường: - 2 $\mathrm{SD} \leq \mathrm{Z}$ - score $\leq+2 \mathrm{SD}$.

- Đánh giá chỉ số Z - score BMI theo tuổi:

+ SDD thể gầy còm: $Z$ - score < - 2 SD.

+ Tình trạng dinh dưỡng bình thường: - 2 $\mathrm{SD} \leq \mathrm{Z}$ - score $\leq+1 \mathrm{SD}$.

+ Thừa cân: + 1SD $<Z$ - score $<+2$ SD

+ Béo phì: Z - score $\geq+2$ SD.

\section{Phương pháp xử lý số liệu}

Số liệu được làm sạch, mã hóa, nhập trên phần mềm Epi data 3.1 và được xử lý trên phần mềm Microsoft Office Exel 2007 và SPSS 20.0. Các biến định tính được so sánh bằng kiểm định Chi - square hoặc Fisher Exact test. Các giá trị có ý nghĩa thống kê khi $p<0,05$ theo 2 phía.

\section{4. Đạo đức nghiên cứu}

Số liệu bài báo là một phần số liệu của đề tài cấp Bộ mã số B2019 - TNA - 13 được phê duyệt theo quyết định số 5652/QĐ - BGDĐT ngày 28/12/2018.

Đề tài tuân thủ quy trình xét duyệt của Hội đồng Đạo đức của trường Đại học $Y$ - Dược Thái Nguyên số 896/ĐHYD - HĐĐĐ ngày 8 tháng 8 năm 2019. Đồng thời được sự đồng ý 
của Phòng Giáo dục và Đào tạo và hai trường PTDTNT THCS huyện Yên Bình và huyện Trấn Yên, tỉnh Yên Bái. Kết quả nghiên cứu được giữ bí mật và các thông tin được sử dụng đúng mục đích nghiên cứu.

\section{KẾT QUẢ}

\section{Một số thông tin chung của đối tượng nghiên cứu}

Kết quả bảng 1 cho thấy số học sinh tham gia nghiên cứu là 535 học sinh, trong đó học sinh nữ chiếm tỷ lệ cao hơn nam giới ở cả hai trường. Độ tuổi của học sinh tham gia nghiên cứu phân bố đồng đều từ 11 đến 14 tuổi, chiếm tỷ lệ cao nhất là học sinh ở độ tuổi 13 (26,5\%), chiếm tỷ lệ thấp nhất là học sinh 14 tuổi (22,6\%). Phần lớn học sinh hai trường PTDTNT THCS là người dân tộc Tày chiếm tỷ lệ 35,7\%, tiếp theo là dân tộc Dao 29,9\%.

Bảng 1. Thông tin chung của đối tượng nghiên cứu

\begin{tabular}{|c|c|c|c|}
\hline & \multirow[t]{2}{*}{ Đặc điểm } & \multicolumn{2}{|c|}{$\begin{array}{l}\text { Chung } \\
(n=535)\end{array}$} \\
\hline & & Số lượng (n) & Tỷ lệ \% \\
\hline \multirow{4}{*}{ Tuổi } & 11 tuổi & 136 & 25,4 \\
\hline & 12 tuổi & 136 & 25,4 \\
\hline & 13 tuổi & 142 & 26,5 \\
\hline & 14 tuổi & 121 & 22,6 \\
\hline \multirow{2}{*}{ Giới tình } & Nam & 194 & 36,3 \\
\hline & Nũr & 341 & 63,7 \\
\hline \multirow{6}{*}{ Nhóm dân tộc } & Tày & 191 & 35,7 \\
\hline & Dao & 160 & 29,9 \\
\hline & Cao Lan & 65 & 12,1 \\
\hline & Mường & 36 & 6,7 \\
\hline & Mông & 36 & 6,7 \\
\hline & Khác & 47 & 8,8 \\
\hline
\end{tabular}

2. Tình trạng dinh dưỡng của học sinh dân tộc thiểu số trường phổ thông dân tộc nội trú trung học cơ sở tại 2 huyện của tỉnh Yên Bái

Kết quả bảng 2 cho thấy tỷ lệ SDD chung của học sinh dân tộc thiểu số tại 2 huyện của tỉnh Yên Bái là 18,5\%, trong đó $15,0 \%$ học sinh SDD thể thấp còi, 4,5\% học sinh SDD thể gầy còm. Trường PTDTNT THCS huyện Trấn Yên có tỷ lệ học sinh SDD thể thấp còi, SDD thể gầy còm cũng như tỷ lệ suy dinh dưỡng chung cao hơn so với những tỷ lệ này ở học sinh trường PTDTNT THCS huyện Yên Bình, sự khác biệt có ý nghĩa thống kê ( $p<0,05)$.

Kết quả bảng 3 cho thấy tỷ lệ học sinh TC - BP chung ở 2 trường PTDTNT THCS của tỉnh Yên Bái là 7,3\%. Tỷ lệ học sinh TC - BP của trường PTDTNT THCS huyện Yên Bình là 9,2\% và 1,8\%, cao hơn so với tỷ lệ học sinh TC - BP của trường PTDTNT THCS huyện Trấn Yên, sự khác biệt có ý nghĩa thống kê $(p<0,05)$. 
Bảng 2. Tình trạng suy dinh dưỡng của học sinh dân tộc thiểu số trường PTDTNT THCS tại huyện Yên Bình và huyện Trấn Yên, tỉnh Yên Bái $(n=535)$

\begin{tabular}{|c|c|c|c|c|c|c|c|}
\hline \multirow[t]{2}{*}{$\begin{array}{l}\text { Tình trạng suy } \\
\text { dinh dưỡng }\end{array}$} & \multicolumn{2}{|c|}{$\begin{array}{l}\text { Chung } \\
(n=535)\end{array}$} & \multicolumn{2}{|c|}{$\begin{array}{c}\text { Trưò̀ng PTDTNT } \\
\text { THCS huyện Yên } \\
\text { Bình (n= 273) }\end{array}$} & \multicolumn{2}{|c|}{$\begin{array}{l}\text { Trường PTDTNT } \\
\text { THCS huyện Trấn } \\
\text { Yên (n= 262) }\end{array}$} & \multirow[t]{2}{*}{$\mathbf{p}$} \\
\hline & $n$ & $\%$ & $\mathrm{n}$ & $\%$ & $n$ & $\%$ & \\
\hline Thể thấp còi & 80 & 15,0 & 33 & 12,1 & 47 & 17,9 & $>0,05$ \\
\hline Thể gầy còm & 24 & 4,5 & 7 & 2,6 & 17 & 6,5 & $<0,05$ \\
\hline Chung & 99 & 18,5 & 38 & 13,9 & 27 & 23,3 & $<0,05$ \\
\hline
\end{tabular}

Bảng 3. Tình trạng thừa cân, béo phì của học sinh dân tộc thiểu số trường PTDTNT THCS tại huyện Yên Bình và huyện Trấn Yên, tỉnh Yên Bái $(n=535)$

\begin{tabular}{|c|c|c|c|c|c|c|c|}
\hline \multirow[t]{2}{*}{$\begin{array}{l}\text { Tình trạng thừa } \\
\text { cân, béo phì }\end{array}$} & \multicolumn{2}{|c|}{$\begin{array}{l}\text { Chung } \\
(n=535)\end{array}$} & \multicolumn{2}{|c|}{$\begin{array}{l}\text { Trưò̀ng PTDTNT } \\
\text { THCS huyện Yên } \\
\text { Bình (n= 273) }\end{array}$} & \multicolumn{2}{|c|}{$\begin{array}{l}\text { Trường PTDTNT } \\
\text { THCS huyện Trấn } \\
\text { Yên (n = 262) }\end{array}$} & \multirow[t]{2}{*}{$\mathbf{p}$} \\
\hline & $\mathbf{n}$ & $\%$ & $\mathrm{n}$ & $\%$ & $\mathbf{n}$ & $\%$ & \\
\hline Thừa cân & 33 & 6,2 & 25 & 9,2 & 8 & 3,1 & $<0,05$ \\
\hline Béo phì & 6 & 1,1 & 5 & 1,8 & 1 & 0,4 & $<0,05$ \\
\hline $\begin{array}{l}\text { Thừa cân, } \\
\text { béo phì }\end{array}$ & 39 & 7,3 & 30 & 11,0 & 9 & 3,5 & $<0,05$ \\
\hline
\end{tabular}

Kết quả bảng 4 cho thấy tại hai trường PTDTNT THCS tỉnh Yên Bái, tỷ lệ học sinh SDD thể thấp còi có xu hướng tăng khi tuổi của học sinh tăng lên, từ 26,2\% ở độ tuổi 11 lên 27,5\% khi ở độ tuổi 14, tuy nhiên sự khác biệt không có ý nghĩa thống kê. Tỷ lệ học sinh SDD thể gầy còm có xu hướng ngược lại với tỷ lệ trên, khi ở lứa tuổi 11 có $33,3 \%$ trẻ bị SDD, thì đến 14 tuổi tỷ lệ này đã giảm còn $16,7 \%$. Tỷ lệ học sinh bị TC - BP cao nhất ở lứa tuổi 13 là 38,5\%, thấp nhất ở độ tuổi 14 với tỷ lệ 10,3\%. Tuy nhiên sự khác biệt về tình trạng dinh dưỡng và tuổi của học sinh đều không có ý nghĩa thống kê $(p>0,05)$.

Bảng 4. Tình trạng dinh dưỡng theo tuổi của học sinh dân tộc thiểu trường PTDTNT THCS tại huyện Yên Bình và huyện Trấn Yên, tỉnh Yên Bái ( $\mathrm{n}=535)$

\begin{tabular}{|c|c|c|c|c|c|c|c|c|c|}
\hline \multirow[t]{2}{*}{ Tình trạng dinh dưỡng } & \multicolumn{2}{|c|}{$\begin{array}{c}11 \text { tuổi } \\
(n=136)\end{array}$} & \multicolumn{2}{|c|}{$\begin{array}{c}12 \text { tuổi } \\
(n=136)\end{array}$} & \multicolumn{2}{|c|}{$\begin{array}{c}13 \text { tuổi } \\
\text { (n= 142) }\end{array}$} & \multicolumn{2}{|c|}{$\begin{array}{c}14 \text { tuổi } \\
(n=121)\end{array}$} & \multirow[t]{2}{*}{$\mathbf{p}$} \\
\hline & $\mathbf{n}$ & $\%$ & $\mathbf{n}$ & $\%$ & $\mathbf{n}$ & $\%$ & $\mathbf{n}$ & $\%$ & \\
\hline Thấp còi & 21 & 26,2 & 14 & 17,5 & 23 & 28,7 & 22 & 27,5 & $>0,05$ \\
\hline Gầy còm & 8 & 33,3 & 5 & 20,8 & 7 & 29,2 & 4 & 16,7 & $>0,05$ \\
\hline $\begin{array}{l}\text { Thừa cân, } \\
\text { béo phì }\end{array}$ & 9 & 23,1 & 11 & 28,2 & 15 & 38,5 & 4 & 10,3 & $>0,05$ \\
\hline
\end{tabular}




\section{Bảng 5. Tình trạng dinh dưỡng theo giới của học sinh dân tộc dân tộc thiểu sốtrường PTDTNT THCS tại huyện Yên Bình và huyện Trấn Yên, tỉnh Yên Bái ( $n=535)$}

\begin{tabular}{|c|c|c|c|c|c|}
\hline \multirow{2}{*}{ Tình trạng dinh dưỡng } & \multicolumn{2}{|c|}{ Nam $(n=194)$} & \multicolumn{2}{|c|}{ Nữ $(n=341)$} & \multirow{2}{*}{$\mathbf{p}$} \\
\hline & $\mathrm{n}$ & $\%$ & $\mathrm{n}$ & $\%$ & \\
\hline Thấp còi & 37 & 19,1 & 43 & 12,6 & $<0,05$ \\
\hline Gầy còm & 11 & 5,7 & 13 & 3,8 & $>0,05$ \\
\hline Thừa cân, béo phì & 13 & 6,7 & 26 & 7,6 & $>0,05$ \\
\hline
\end{tabular}

Kết quả bảng 5 cho thấy nữ giới có tỷ lệ SDD thấp còi $(12,6 \%)$ thấp hơn so với tỷ lệ này ở nam giới (19,1\%), sự khác biệt có ý nghĩa thống kê. Tỷ lệ suy dinh dưỡng thể gầy còm ở nữ $(3,8 \%)$ cũng thấp hơn so với nam giới $(5,7 \%)$, nhưng sự khác biệt không có ý nghĩa thống kê ( $p>0,05)$. Ngược lại, tỷ lệ thừa cân, béo phì ở nữ giới $(7,6 \%)$ cao hơn so với tỷ lệ thừa cân, béo phì ở nam giới $(6,7 \%)$, tuy nhiên sự khác biệt không có ý nghĩa thống kê ( $p>0,05)$.

\section{BÀN LUẤN}

Kết quả nghiên cứu của chúng tôi cho thấy tỷ lệ SDD chung của học sinh tại hai trường PTDTNT THCS là khá cao 18,5\%, trong đó SDD thể thấp còi chiếm tỷ lệ 15,0\% (bảng 2) cao hơn khi so sánh với tỷ lệ này ở trẻ em lứa tuổi học đường (5 - 19 tuổi) trên toàn quốc là 14,8\%. ${ }^{1}$ Tỷ lệ SDD thể thấp còi trong nghiên cứu của chúng tôi cũng cao hơn rất nhiều khi so với kết quả 5,9\% trẻ vị thành niên 11 - 17 tuổi ở các trường trung học cơ sở và phổ thông trung học ở Hà Nội bị SDD. ${ }^{2}$ Điều này có thể giải thích do sự khác biệt về vùng miền, đặc biệt trong kết quả Tổng điều tra dinh dưỡng năm 2020 cũng cho thấy sự khác biệt về tình trạng dinh dưỡng giữa các vùng miền, vùng sâu vùng xa, miền núi so với tình trạng dinh dưỡng của vùng thành thị, nông thôn. ${ }^{1}$

Trong tổng số 535 học sinh tham gia nghiên cứu, có 7,3\% học sinh bị TC - BP (bảng 3), thấp hơn rất nhiều so với tỷ lệ học sinh TC - BP tại thành phố Hải Phòng năm 2019 - 2020 với tỷ lệ TC - BP chung là 29,9\%. Và thấp hơn so với nghiên cứu được thực hiện trên cùng đối tượng nghiên cứu là học sinh trung học cơ sở tại Bắc Ninh (15,8\%). ${ }^{3}$ Kết quả nghiên cứu của chúng tôi cao hơn so với tỷ lệ học sinh các trường
THCS tại huyện Phù Cát, bình Định năm 2017 với tỷ lệ 5,6\% TC - BP. ${ }^{5}$

Kết quả nghiên cứu của chúng tôi còn cho thấy trường PTDTNT THCS huyện Trấn Yên có tỷ lệ học sinh SDD thể thấp còi $(17,9 \%)$ cao hơn so với tỷ lệ này tại trường PTDTNT THCS huyện Yên Bình (12,1\%), tuy nhiên sự khác biệt không có ý nghĩa thống kê ( $p>0,05)$. Tỷ lệ học sinh SDD thể gầy còm $(6,5 \%)$ cao hơn so với tỷ lệ này của học sinh trường PTDTNT THCS huyện Yên Bình (2,6\%), sự khác biệt có ý nghĩa thống kê với $p<0,05$ (bảng 2). Ngược lại với tỷ lệ SDD là tỷ lệ TC - BP của học sinh trường PTDTNT THCS huyện Yên Bình cao hơn so với tỷ lệ TC - BP tại trường PTDTNT THCS huyện Trấn Yên, sự khác biệt có ý nghĩa thống kê (p $<0,05$ ) (bảng 3). Tại 2 trường PTDTNT THCS, không có sự khác biệt về độ tuổi của trẻ với tình trạng dinh dưỡng ( $p>0,05)$ (bảng 4). Không có sự khác biệt về giới tính của trẻ với tình trạng SDD thể gầy còm, với tỷ lệ $\mathrm{TC}$ - BP tại 2 trường PTDTNT THCS (bảng 5). Nữ giới có tỷ lệ SDD thể thấp còi (12,6\%) thấp hơn so với nam giới (19,1\%), sự khác biệt có ý nghĩa thống kê $(p<0,05)$.

Kết quả trên cho thấy mô hình tình trạng dinh dưỡng của trẻ lứa tuổi học đường đang có 
chiều hướng phát triển tương tự mô hình dinh dưỡng của trẻ ở các thành phố lớn, tỷ lệ học sinh bị SDD vẫn còn khá cao trong khi tỷ lệ TC - BP ngày càng tăng và đáng báo động. Hình thái phân hoá này vẫn cho thấy gánh nặng kép về dinh dưỡng đối với mô hình bệnh tật. Do đó, rất cần sự can thiệp kịp thời của gia đình, thầy cô giáo, nhà trường cũng như các ngành liên quan nhằm cải thiện tình trạng dinh dưỡng cho trẻ lứa tuổi học đường.

\section{KÉT LUÂN}

Tỷ lệ SDD chung của học sinh hai trường PTDTNT THCS là 18,5\%, trong đó SDD thể thể thấp còi chiếm tỷ lệ là $15,0 \%$ và thể gầy còm là 4,5\%. Tỷ lệ TC - BP chung của học sinh hai trường PTDTNT THCS là 7,3\%, trong đó béo phì là $6,2 \%$ và thừa cân là $1,1 \%$. Không có sự khác biệt có ý nghĩa thống kê về tỷ lệ SDD cũng như tỷ lệ TC - BP theo độ tuổi của học sinh tại 2 trường PTDTNT THCS thuộc hai huyện của tỉnh Yên Bái $(p>0,05)$.

\section{Lời cảm ơn}

Chúng tôi trân trọng cảm ơn Bộ Giáo dục và Đào tạo, Đại học Thái Nguyên, trường Đại học Y Dược - Đại học Thái Nguyên, Phòng Giáo dục và đào tạo và hai trường PTDTNT THCS huyện Yên Bình và huyện Trấn Yên, tỉnh Yên Bái đã tạo điều kiện thuận lợi cho chúng tôi thực hiện đề tài này.

\section{TÀI LIẸU THAM KHẢO}

1. Bộ Y tế. Kết quả Tổng điều tra Dinh dưỡng năm 2019 - 2020. https://moh.gov.vn/tin - noi bat/ - /asset_publisher/3Yst7YhbkA5j/content/ bo - y - te - cong - bo - ket - qua - tong - dieu tra - dinh - duong - nam - 2019 - 2020. Truy cập ngày 25/5/2021.

2. Trần Thị Lụa, Lê Thị Hợp, bùi Tố Loan. Tình trạng dinh dưỡng và xác định tuổi dậy thì ở trẻ gái vị thành niên tại hai vùng thành phố và nông thôn. 2008, tập 4, số 1, tháng 4.

3. Đỗ Thị Chuyên, Nguyễn Thị Quỳnh Anh, Đỗ Nguyễn Quỳnh Trang, Đỗ Thị Như Trang, Nguyễn Thị Lan Lương, Nguyễn Thị Hồng Hạnh. Tình trạng dinh dưỡng phân loại theo tî lệ mỡ cơ thể ở học sinh 11 - 14 tuổi tại thị xã Từ Sơn, tỉnh Bắc Ninh năm 2019. Tạp chí Khoa học và Công Nghệ Thái Nguyên. 2021; 226 (01):20 - 26.

4. Nguyễn Quang Đức, Dương Thị Hương, Phạm Huy Quyến. Thực trạng dinh dưỡng và một số yếu tố liên quan tới học sinh trường trung học cơ sở Lê Lợi, Hải Phòng năm 2019 - 2020. Tạp chí Y học dự phòng. 2021; tập 31, số 1: 72 - 79 .

5. Lê Thị Bích Ngọc. Tình trạng dinh dưỡng và tần suất tiêu thụ thực phẩm của học sinh từ 12 - 14 tuổi tại 3 trường trung học cơ sở huyện Phù Cát, tỉnh Bình Định. Tạp chí Dinh dưỡng và thực phẩm; tập 13, số 4, tháng 6.

\section{Summary \\ NUTRITIONAL STATUS OF STUDENTS AT THE ETHNIC BOARDING JUNIOR HIGH SCHOOLS IN YEN BAI PROVINCE}

This study was conducted to describe the nutritional status of the ethnic minority students at the ethnic boarding junior high school at Yen Binh district and Tran Yen district, Yen Bai province in 2019. This is a descriptive, cross-sectional method on 535 ethnic minority students. Data was collected by interview with pre-designed questionnaires and direct measurement. The international reference standard was used to assess the students nutritional status. The prevalence of stunting among ethnic minority students accounted for $15.0 \%$, body wasting by 


\section{TAPP CHÍ NGHIÊN CỨU Y HỌC}

malnutrition was $4.5 \%$. The prevalence of overweight and obesity tended to increase with the rate of $7.3 \%$. There was no statistically significant difference in the prevalence of malnutrition as well as the prevalence of overweight and obesity by age among students in the two ethnic boarding junior secondary schools in Yen Binh district and Tran Yen district, Yen Bai province ( $p>0.05)$.

Keywords: Students, Ethnic minorities, ethnic boarding junior secondary school, nutritional status, Yen Binh district, tran Yen district, Yen Bai province. 